\title{
Why Publishing in Journal of Psychological Abnormalities in Children
}

\section{Adel M. Agina*}

Professor, Department of Communication Studies, University of Twente, Netherlands

Our children are our future! All the researchers, novices and professionals, in all areas of knowledge with no exception, are hardly working to make us feel secure about our future, rapidly running to ensure the brightness of our future, drastically wishing to see the seeds of our future growing perfectly, and deeply thinking to be effective contributors to improve our future.

Ironically, despite our future already lives with and among us, the literature, in all terms of research, still lacks the deeply research in all branches and topics of science concerning children's behavioral development especially regarding Psychological Abnormalities in Children, which is the main mission and focus of our journal.

Nowadays, unlimited number of novice and professional researchers, all over the world, still do not find such a scientific place where they can introduce their work to help improving children's live either physiologically or mentally especially when their work is already cross-disciplinary interested research between two or more different topics in one or more branches of sciences. In more specific, when their work include the topics that merge the aspects of children's behavioral developmental with the affordable advanced technology, mainly computers, given the fact that technology affects the children in many and various directions.

Those novice and professional researchers with an interest and cross-disciplinary interests in children's psychological and behavioral development aspects of technology use, especially computer but with limited knowledge of computer itself, will find this journal as interest as the best to submit their work. They will meet high quality of the academic revision with a number of academician-reviewers who already aware and respect their work to help them publishing their work with high quality of presentation style to bridge the knowledge gap and promote research esteem especially concerning Psychological Abnormalities in Children.

The technology and computer, in our mission, are basically demonstrated and introduced as an aid and medium through which children's behavioral development are shaped and expressed, which is the main focus and goal of our mission especially if the outcomes relating to Psychological Abnormalities in Children. This is where your manuscript occupies a position in the list of our highest priority given the cross-disciplinary topic you want to introduce.

Consequentially, our mission is not only aiming to publish regular and cross-disciplinary research, but also the multidisciplinary and interdisciplinary researches in all areas of science that mainly serve the Psychological Abnormalities in Children. In specific, all the researches, studies, experiments, reports, papers, case studies, reviews, short reports (not more than 5-page papers where the author can either present an idea with cohesive theoretical background, but did not completed the research yet that needed for a complete manuscript, or the author just aims to introduce primary results to ensure the reliability), book reviews (comments and critiques associated with strong arguments) at any branch of science concerning children's behavioral development especially those manuscripts that serve Psychological Abnormalities in Children.

The preferable areas of science that our mission works with include, but not limited to in terms of cross-disciplinary research, are: psychology and educational psychology, psychiatry, cognitive and meta-cognitive, communication studies, creative thinking, personality, social interactions, artificial intelligent and children-media interaction. Any other branch of science is very welcome as long as the topic is relating to children's behavioral development aspects that may help improving children's current and future live especially in relation with Psychological Abnormalities in Children.

Although our mission is completely relating to Psychological Abnormalities in Children, specialists in preparing children's edutainment applications, especially designers and programmers, are highly encouraged to submit their ideas on how can the children's cognitive overload before, during, and after the experiment be technically avoided when children's conducted as participants in such a cross-disciplinary experiment to, mainly, help evaluating the outcomes of the aforementioned topics.

In specific, how can children's cognitive overload be eliminated, or at least minimized, during the three experimental processes: before the children start, during the experiment, and after the experiment, which is the most significant obstacle the research regarding children's behavioral development still encounter. Designers and programmers are also very encouraged to submit their work on how can the sophisticated technology help the research in children's behavioral development and especially to serve Psychological Abnormalities in Children. They are also very encouraged to share their work/ideas with specialists in children's behavioral development and to submit their joint results. This kind of results and research occupy high position in the list of our mission's highest priority.

The main topics relevant to our mission among the different areas of science include, but not limited to, are the following:

- Children's Self-Regulation.

- Children's Private Speech.

- Children's Social Speech.

- Children'sThinking Aloud.

- Children's Edutainment and Learning.

- Children's Gaming and Violence.

- Children's Compulsory-Interaction.

- Children's Undesirable-Interaction.

- Children's Inner-Interaction.

- Children's Spontaneous-Interaction.

- Computer-based Methodologies with Children.

*Corresponding author: Adel M. Agina, Professor, Department of Communication Studies, University of Twente, Netherlands, Tel: +31534893576/+218924887110; Fax: +31534891104; E-Mail: a.m.agina@utwente.nl.

Received January 16, 2015; Accepted January 16, 2015; Published January 25 2015

Citation: Agina AM (2015) Why Publishing in Journal of Psychological Abnormalities in Children. J Psychol Abnorm Child 4: e103. doi:10.4172/2329-9525.1000e103

Copyright: $\odot 2015$ Agina AM, et al. This is an open-access article distributed under the terms of the Creative Commons Attribution License, which permits unrestricted use, distribution, and reproduction in any medium, provided the original author and source are credited. 
Citation: Agina AM (2015) Why Publishing in Journal of Psychological Abnormalities in Children. J Psychol Abnorm Child 4: e103. doi:10.4172/2329$9525.1000 \mathrm{e} 103$

Page 2 of 2

Most importantly, the cross-disciplinary research among the aforementioned topics especially those with new ideas that supported by reliable results regarding Psychological Abnormalities in Children stays at the top of our mission's highest priority. 